Check for updates

Royal Surrey County Hospital NHS Foundation Trust, Guildford, UK

2 Department of Health Policy, London School of Economics, UK

3 London, UK

4 Department of Medical Ethics and Health Policy, University of Pennsylvania, USA

Correspondence to: T Bartholomew tb.public@mailbox.org Cite this as: $B M J$ 2022;376:e062188 http://dx.doi.org/10.1136/bmj-2020-062188 Published: 07 March 2022

\title{
Use of adherence monitoring in drug contracts tied to outcomes: put patients first
}

\section{Theodore Bartholomew and colleagues examine how contracts linking drug payments to effectiveness may affect patient trust and autonomy}

\author{
Theodore Bartholomew, ${ }^{1}$ Huseyin Naci, ${ }^{2}$ Emma Robertson, ${ }^{3}$ Harald Schmidt ${ }^{4}$
}

Healthcare payers, including NHS England, ${ }^{1}$ are making increasing use of outcomes based contracts for new drugs. ${ }^{12}$ Under these contracts payment for drugs is tied to real world effectiveness instead of a fixed price per unit. ${ }^{3} \mathrm{~A}$ typical agreement might entail a manufacturer either wholly or partially refunding drug costs if the agreed outcome threshold (cure, reduction in mortality, biochemical outcome) is not met. Although these contracts can facilitate access to new drugs when cost effectiveness is unclear, they present challenges with measuring outcomes and have potential for political and commercial conflict of interests. ${ }^{3-5}$

Patients' adherence to drugs attains new importance in outcomes based contracts. Manufacturers may argue that suboptimal adherence is responsible for a poor outcome rather than ineffectiveness whereas payers may argue the opposite. Medication non-adherence is widespread with rates of up to $50 \%$ reported in hypertension, diabetes, asthma and cancer, and the reasons for it are complex and poorly understood..$^{6-8}$ One way to help assess whether outcomes reflect effectiveness is to include a requirement for adherence monitoring in outcomes based contracts. This has clear measurement advantages for both manufacturer and payer, but whether it is in the interests of patients is unclear. We consider how outcomes based contracts and adherence monitoring might affect patients within a nationalised health system such as the NHS.

\section{Use of outcomes based contracts}

The confidential manner in which drug contracts are negotiated ${ }^{9}$ has obscured the emergence of outcomes based contracts globally. The first publicly disclosed contracts were in the US in the mid-1990s. ${ }^{2}$ In one example, Merck refunded up to six months of prescription costs (to both patient and payer) if simvastatin plus diet did not lower cholesterol to target levels. ${ }^{5}$ In England, North Staffordshire Health Authority agreed a similar contract with Parke-Davis (Pfizer) in 2000. ${ }^{10}$

The first national outcomes based contract in the UK was for four multiple sclerosis drugs. Patients were monitored using a clinical disability score and the price was adjusted to achieve a cost per quality adjusted life year (QALY) of $€ 36$ ooo or less, effectively leveraging the contracts to close data gaps. ${ }^{11}$ More recently, NHS England has implemented a "pay per cure" contract for drugs to treat hepatitis C in which the manufacturer is paid only if the patient has a sustained viral response (table 1). ${ }^{13}$ NHS England has stated that a "series" of outcomes based contracts have been agreed in recent years, although few have been publicly disclosed. ${ }^{1}$ Greater Manchester Health and Social Care Partnership has also said it intends to introduce them for cancer drugs when the NHS and manufacturers struggle to agree a price. ${ }^{14}$ Use of outcomes based contracts across Europe and the US is expected to increase as the contracts have potential benefits for both payers and drug companies. ${ }^{215}$ 


\begin{tabular}{|c|c|c|c|c|}
\hline Condition & Manufacturer(s) & Drug(s) & Year & Outcome agreement \\
\hline Hypercholesterolaemia & Parke-Davis (Pfizer) & Atorvastatin & 2000 & $\begin{array}{l}\text { Manufacturer agreed to rebate North } \\
\text { Staffordshire Health Authority if } \\
\text { threshold percentages of defined } \\
\text { patient cohorts did not achieve target } \\
\text { cholesterol levels }\end{array}$ \\
\hline \multirow[t]{2}{*}{ Multiple sclerosis } & Biogen, Bayer, EMD Serono & Interferon beta & \multirow[t]{2}{*}{2003} & \multirow{2}{*}{$\begin{array}{l}\text { Price adjustments made at intervals } \\
\text { to achieve an agreed cost per QALY } \\
\text { of } f 36000 \text { or less }\end{array}$} \\
\hline & Teva & Glatiramer acetate & & \\
\hline Multiple myeloma & Johnson\&Johnson & Bortezomib & 2006 & $\begin{array}{l}\text { Manufacturer reimburses NHS for the } \\
\text { first four cycles if there is no } \\
\text { response to treatment (defined as } \\
50 \% \text { decrease in serum } \mathrm{M} \text { protein) }{ }^{5}\end{array}$ \\
\hline Psoriasis & Novartis & Secukinumab & 2017 & $\begin{array}{l}\text { Participating NHS trusts are provided } \\
\text { with an (undisclosed) rebate if } \\
\text { Psoriasis Area Severity Index score } \\
\text { is not reduced by >90\% after } 16 \\
\text { weeks of treatment } 12\end{array}$ \\
\hline Multiple sclerosis & Merck & Cladribine & 2017 & Undisclosed $^{1}$ \\
\hline \multirow[t]{3}{*}{ Hepatitis C } & Gilead & $\begin{array}{l}\text { Ledipasvir-sofosbuvir (Harvoni) } \\
\text { Sofosbuvir-velpatasvir (Epclusa) }\end{array}$ & \multirow[t]{3}{*}{2018} & \multirow{3}{*}{$\begin{array}{l}\text { NHS only pays for medication if a } \\
\text { patient is cured (sustained virological } \\
\text { response at } \geq 12 \text { weeks after } \\
\text { treatment completion) }{ }^{13}\end{array}$} \\
\hline & Merck, Sharpe and Dohme & Elbasvir-grazoprevir (Zepatier) & & \\
\hline & AbbVie & $\begin{array}{l}\text { Glecaprevir-pibrentasvir (Maviret) } \\
\text { Ombitasvir-paritaprevir-ritonavir } \\
\text { (Viekirax) } \\
\text { Dasabuvir (Exviera) }\end{array}$ & & \\
\hline
\end{tabular}

Payers such as NHS England are primarily interested in using outcomes based contracts to more tightly control a drug's costs relative to its outcomes, and to provide access to expensive drugs when there is uncertainty about effectiveness and affordability. ${ }^{914}$ In theory, the contracts allow additional outcomes data to be gathered so that the drug can be priced according to its real world value. ${ }^{14}$

For manufacturers, one attraction of these contracts is that they can help show their product's effectiveness over competitors. ${ }^{9}$ There are concerns, however, about being held accountable for outcomes given manufacturers lack of control over how a medication is prescribed or taken. ${ }^{9}$ In one publicly disclosed US contract, a payer was given additional discounts if administrative data showed that diabetes patients had been adherent, although specific stipulations were not disclosed. ${ }^{3}$ As contracts are usually confidential, it is difficult to determine how often adherence is tied to payment, but this is unlikely to be the only example.

\section{Adherence monitoring}

Adherence has previously been defined as "the extent to which patients take medications as prescribed." ${ }^{16}$ Newer conceptualisations of adherence, however, recognise its complexity by appreciating the need to consider both multilevel (regimen, patient, provider, health system) and multidimensional (initiation, implementation, and persistence) factors. ${ }^{71617}$ There is no single ideal measure of adherence, and no universally accepted threshold for defining adherence. ${ }^{1618}$ However, it is important to capture subjective measures (those that evaluate a patient's beliefs and explanations) alongside objective measures (those that capture a record of medication use) in any assessment. ${ }^{18}$

Health systems routinely record many metrics (eg, blood pressure, obesity), ${ }^{19}$ yet adherence is not recorded and may only be informally checked by clinicians. Recently, multiple technologies have emerged that monitor adherence remotely (box 1). ${ }^{20}$ Evidence on the acceptability of adherence monitoring technologies and their ability to improve patient outcomes is typically poor. ${ }^{21-25}$ The effectiveness of different methods to improve adherence varies and depends on disease area studied and the resources allocated. ${ }^{21-25}$ Although their utility and cost effectiveness remain unclear, these technologies are of particular relevance to outcomes based contracts. ${ }^{26}{ }^{27}$ Remote monitoring may provide greater accuracy than, for example, pharmacy dispensing reports, which the NHS currently uses to monitor treatment completion in patients with hepatitis C. ${ }^{28}$

\section{Box 1: Remote adherence monitoring technologies}

Text messages/electronic diary

- Provider prompts patient by text message or electronic diary

- Patient reports adherence by text message or electronic diary Signalling bottle

- Pill bottle flashes light when pill should be taken

- Pill bottle automatically sends a message to a computer/smartphone each time the cap is removed

- Computer or smartphone records whether or when pill bottle was opened

\section{Video check (with healthcare professional)}

- Professional observes patient taking pill using video platform

- Professional records whether or when pill was taken

Video check (automated)

- App with facial and pill recognition capability analyses patient through smartphone camera

- App records whether or when pill was taken

Signalling pill

- Sensor is embedded within a pill

- Smartphone app reminds patient when pill should be taken 
- When pill reaches stomach, signal is sent to a receiver which relays information to a smartphone recording when pill was taken

Measurement of physiological or biochemical marker

- Measurement of physiological markers (eg, heart rate or blood pressure)

- Measurement of biochemical markers (eg, blood glucose monitoring)

\section{Implications for patients}

Patients have a clear interest in their health. Whether a patient wishes or is able to be adherent depends on numerous complex factors, many of which are grounded in the relationships they have built with their medical teams and the communication between those teams. ${ }^{717}$ Patients, however, often cite forgetfulness as a factor, and find adherence more challenging the more frequently a medication has to be taken. ${ }^{726}$ Typically, adherence is high for patients with acute conditions but drops steeply for chronic conditions after six months of treatment. ${ }^{26}$ Consequently, if patients choose to use adherence monitoring as part of a shared decision making process, it may support them to act autonomously. ${ }^{29}$ Conversely, monitoring (particularly objective monitoring alone, which simplistically measures adherence as a number without understanding the barriers a patient may face to being adherent) may increase responsibility on patients in ways that offer no or marginal additional benefit and undermine, rather than support, their interests.

Patients have many reasons for not taking their medications. ${ }^{717}$ Side effects, for example, are a major predictor of non-adherence because they reduce quality of life. ${ }^{26}$ Adherence may also depend on the drug's perceived benefit. While adherence monitoring may help improve clinicians' understanding of side effects, ${ }^{30}$ patients may feel uncomfortable if monitoring causes them to be labelled in an unqualified manner as "non-adherent."

Concerns also exist about whether adherence monitoring may unduly restrict patient liberty and autonomy. ${ }^{29}{ }^{31}$ Expectations to use adherence monitoring could undermine voluntariness or even become coercive if, for example, a patient is concerned that non-use will harm the relationship with their physician. Another concern stems from tying financial rewards or penalties to adherence. The NHS does not presently allow financial penalties, but incentives have been trialled, for example, in smoking cessation and weight loss programmes. ${ }^{32} 33$ Providing financial incentives to patients could compromise consent, particularly for patients from marginalised groups for which incentives could have disproportionate leverage. ${ }^{34}$ Others may have concerns that their confidential information might be sold to third parties and potentially linked back to them. ${ }^{30}$ Further testing in clinical practice is required to understand fully the acceptability of adherence monitoring, but patients have already raised concerns about how it may affect face-to-face contact time, confidentiality, and difficulties using the technologies. 3536

\section{Societal perspective can influence personal responsibility}

An important consideration from the societal perspective is the patient's moral (and in some cases, legal ${ }^{37}$ ) obligations to consider how non-adherence may affect the health of others. Public health risk, for example, is the justification for using directly observed therapy in some patients with tuberculosis. ${ }^{37}$ The international response to the covid-19 pandemic shows that public health can motivate obligations that go far beyond the individual. ${ }^{38}$ In principle, the case for using adherence monitoring on public interest grounds strengthens as risk of harm to others increases. Yet, it also increases healthcare professionals' obligations to communicate with patients about the reasons why adherence may be important, which is difficult to do properly with limited consultation time.

Within a nationalised health system such as the NHS, there is a societal expectation that the public should use collective resources responsibly, such as by keeping their appointments. ${ }^{394^{\circ}}$ In England, these responsibilities are set out in the NHS Constitution, which states: "Please follow the course of treatment which you have agreed, and talk to your clinician if you find this difficult." 39 Yet, this appeal also extends the other way, leading citizens to hold expectations about their treatment and how, for example, their data should not be used for profit. Societal expectation could extend to medication non-adherence, given its opportunity cost (health gains forgone) is estimated to be more than $£ 500 m$ annually in the UK. ${ }^{41}$ This, however, must be considered carefully alongside the wide ranging and legitimate reasons that patients may have for not taking their medications. ${ }^{717}$

\section{Risks to patient-provider relationship and health system}

Critically, adherence monitoring seems likely to affect one of the fundamental tenets of healthcare: the patient-provider relationship. The interactions between professionals and patients are already highly variable, and trust can be eroded if medications do not have desired consequences, if professionals fail to communicate effectively, and if the patients have concerns about being taken advantage of. $4^{2}$

Combining outcomes based contracts with adherence monitoring is likely to have unpredictable consequences. Physicians, for example, may exert implicit or explicit pressure on patients to use adherence monitoring to gain insights into how they take their medications. Behaviours may also be influenced by the amount of public information available for each contract, including knowledge of the potential financial implications of non-adherence. Both the UK National Institute for Health and Care Excellence (NICE) and the Association of the British Pharmaceutical Industry (ABPI) acknowledge that all relevant information about drugs being appraised should be put in the public domain. ${ }^{43}$ However, clinical and economic data of importance to patients, clinicians, and researchers are often redacted. ${ }^{44}$ Contractual stipulations relating to adherence monitoring and the effect of non-adherence on reimbursement are of direct relevance to patients, the public, and health system and should therefore be in the public domain.

\section{Patient centred approach}

Use of outcomes based contracts is likely to continue to increase, driven by the commercial interests of manufacturers and the economic interests of payers to limit the budgetary impact of high cost drugs. Patients, society, and health providers-particularly in a nationalised system using collective resources such as the NHS-have a right to greater involvement in how these contracts develop and are negotiated. This process should begin with the creation of a new transparency agreement between ABPI and NICE that is co-developed with patients. Additionally, we echo calls for the regulation of data transparency in drug appraisals. 44

The importance of using both subjective and objective adherence monitoring must be recognised, as well as a more nuanced appreciation of the multilevel and multidimensional nature of non-adherence. The effect on patients who are reluctant to use adherence monitoring must also be considered.

The effects on behaviour and patient-provider relationships are likely to vary considerably according to disease characteristics, patient population, and the transparency with which contracts have 
been negotiated. Patient and public expectations will also be different across nationalised, privatised, and insurance based health systems, and will vary according to cultural and societal contexts.

Wider debate and more qualitative research needs to be undertaken with patients, healthcare professionals, and policy makers on outcomes based contracts and adherence monitoring to understand acceptability and feasibility. Both adherence monitoring technologies and the contracts they are meant to support will fail if they are not created in partnership with patients and with patient centredness as the overarching goal.

\section{Key messages}

- Outcomes based contracts seek to align payments for drugs with their real world outcomes and are gaining traction worldwide, including in the UK

- The contracts raise novel issues for patients as medication adherence may affect the revenues of manufacturers and costs to the health system

- Adherence is a complex issue, and monitoring technologies may exacerbate tensions created by the contracts between patients and financial outcomes

- Patient centredness and transparency must be prioritised in the development of contracts and any use of adherence monitoring technologies

Contributors and sources: TB has a special interest in medical ethics and health policy. HN conducts research and teaches on pharmaceutical policy and has written extensively on pharmaceutical economics, policy, and regulation. ER is a metastatic breast cancer patient and campaigner who has worked on patient and public involvement work with Cancer Research UK, the Professional Record Standards Body, and Imperial Cancer Research. She is a trustee for the grassroots cancer charity Mission Remission. HS's research focuses on reducing disadvantage and improving opportunity for vulnerable populations in health promotion and priority setting. The idea for the article was conceived by HS. TB wrote the first draft and led all subsequent revisions. TB, HN, and HS contributed to all subsequent drafts. ER contributed to later drafts, providing critical patient perspective. All have read and agreed to the final version. TB is the guarantor.

Competing interests: We have read and understood BMj policy on declaration of interests and have no interests to declare.

Provenance and peer review: Not commissioned; externally peer reviewed.

NHS England. NHS England strikes new deals to make two new innovative treatments available routinely on the NHS. 2017. https://www.england.nhs.uk/2017/11/nhs-england-strikes-new-dealsto-make-two-new-innovative-treatments-available-routinely-on-the-nhs/

2 Nazareth T, Ko JJ, Sasane R, etal. Outcomes-based contracting experience: research findings from US and European stakeholders. J Manag Care Spec Pharm 2017;23:1018-26. doi: 10.18553/jmcp.2017.23.10.1018 pmid: 28944734

3 Neumann PJ, Chambers JD, Simon F, Meckley LM. Risk-sharing arrangements that link payment for drugs to health outcomes are proving hard to implement. Health Aff (Millwood) 2011;30:2329-37. doi: 10.1377/hlthaff.2010.1147 pmid: 22147861

4 Seeley E, Kesselheim AS. Outcomes-based pharmaceutical contracts: an answer to high US drug spending? Issue Brief (Commonw Fund) 2017;2017:1-8.pmid: 28953345

5 Carlson JJ, Sullivan SD, Garrison LP, Neumann PJ, Veenstra DL. Linking payment to health outcomes: a taxonomy and examination of performance-based reimbursement schemes between healthcare payers and manufacturers. Health Policy 2010;96:179-90.

doi: 10.1016/j.healthpol.2010.02.005 pmid: 20226559

6 McDonald HP, Garg AX, Haynes RB. Interventions to enhance patient adherence to medication prescriptions: scientific review. JAMA 2002;288:2868-79. doi: 10.1001/jama.288.22.2868 pmid: 12472329

7 Brown MT, Bussell JK. Medication adherence: WHO cares? Mayo Clin Proc 2011;86:304-14 doi: 10.4065/mcp.2010.0575 pmid: 21389250

8 Moon Z, Moss-Morris R, Hunter MS, Norton S, Hughes LD. Nonadherence to tamoxifen in breast cancer survivors: A 12 month longitudinal analysis. Health Psychol 2019;38:888-99. doi: 10.1037/hea0000785 pmid: 31343218

9 Garrison LP, JrCarlson JJ, Bajaj PS, etal. Private sector risk-sharing agreements in the United States: trends, barriers, and prospects. Am J Manag Care 2015;21:632-40

10 Chapman S, Reeve E, Rajaratnam G, Neary R. Setting up an outcomes guarantee for pharmaceuticals: new approach to risk sharing in primary care. BM/2003;326:707-9. doi: 10.1136/bmj.326.7391.707 pmid: 12663411

11 Pickin M, Cooper CL, Chater T, etal. The Multiple Sclerosis Risk Sharing Scheme Monitoring Study -early results and lessons for the future. BMC Neuro/2009;9:1. doi: 10.1186/1471-2377-9-1
12 Armendariz Y, Evans C, Halliday A, Walsh JJ. The role of outcomes-based models for the reimbursement of medicines in the UK National Health Service. Value Health 2019;22:S720doi: 10.1016/j.jval.2019.09.1687

13 NHS England. NHS England sets out plans to be first in the world to eliminate Hepatitis C. NHS England blog. 29 Jan 2018. https:/www.england.nhs.uk/2018/01/hepatitis-c-2/2/

14 Cole A, Cubi-Molla P, Pollard J, et al. Making outcome-based payment a reality in the NHS. 2019 https://www.cancerresearchuk.org/sites/default/files/obp_finaL_report_pdf.pdf

15 Seeley E, Chimonas S, Kesselheim AS. Can outcomes-based pharmaceutical contracts reduce drug prices in the US? A mixed methods assessment. J Law Med Ethics 2018;46:952-63doi: 10.1177/1073110518821995

16 Stirratt MJ, Curtis JR, Danila MI, Hansen R, Miller MJ, Gakumo CA. Advancing the science and practice of medication adherence. J Gen Intern Med 2018;33:216-22. doi: 10.1007/s11606-017-4198-4 pmid: 29204969

17 Viswanathan $\mathrm{M}$, Golin CE, Jones $\mathrm{CD}$, etal. Interventions to improve adherence to self-administered medications for chronic diseases in the United States: a systematic review. Ann Intern Med 2012;157:785-95. doi: 10.7326/0003-4819-157-11-201212040-00538 pmid: 22964778

18 Lam WY, Fresco P. Medication adherence measures: an overview. Biomed Res Int 2015;2015:217047. doi: 10.1155/2015/217047 pmid: 26539470

19 NHS England. Quality and Outcomes Framework guidance for 2021/22. 2021. https://www.nhsemployers.org/news/2012/02/quality-and-outcomes-framework-guidance-for201213

20 McCormick JB, Green MJ, Shapiro D. Medication nonadherence: there's an app for that! Mayo Clin Proc 2018;93:1346-50. doi: 10.1016/j.mayocp.2018.05.029 pmid: 30170740

21 Chai PR, Goodman G, Bustamante M, et al. Design and delivery of real-time adherence data to men who have sex with men using antiretroviral pre-exposure prophylaxis via an ingestible electronic sensor. AIDS Behav 2020.

22 Volpp KG, Troxel AB, Mehta SJ, etal. Effect of electronic reminders, financial incentives, and social support on outcomes after myocardial infarction: the heartstrong randomized clinical trial. JAMA Intern Med 2017;177:1093-101. doi: 10.1001/jamainternmed.2017.2449 pmid: 28654972

23 Story A, Aldridge RW, Smith CM, etal. Smartphone-enabled video-observed versus directly observed treatment for tuberculosis: a multicentre, analyst-blinded, randomised, controlled superiority trial. Lancet 2019;393:1216-24. doi: 10.1016/S0140-6736(18)32993-3 pmid: 30799062

24 Leo S, Gentry-Brown K, Makanji H, Prasla K, Pothier L, Cutts S. Impact of a smartphone-based artificial intelligence platform on hepatitis $\mathrm{C}$ adherence in a real-world population. Academy of Managed Care Pharmacy, 2019. https://www1.magellanrx.com/documents/2019/04/research_impact-of-smartphone-based-artificial-intelligence-platform-on-hepatitis-c-adherence-in-a-realworld-population.pdf/

25 Finitsis DJ, Pellowski JA, Johnson BT. Text message intervention designs to promote adherence to antiretroviral therapy (ART): a meta-analysis of randomized controlled trials. PLoS One 2014;9:e88166. doi: 10.1371/journal.pone.0088166 pmid: 24505411

26 Osterberg L, Blaschke T. Adherence to medication. N Engl J Med 2005;353:487-97. do: 10.1056/NEJMra050100 pmid: 16079372

27 Neiheisel MB, Wheeler KJ, Roberts ME. Medication adherence part one: understanding and assessing the problem. J Am Assoc Nurse Pract 2014;26:49-55. doi: 10.1002/2327-6924.12099 pmid: 24382862

28 Lothian NHS. Pharmaceutical care of patients requiring support with adherence to complex medication regimes. 2017. https://www.communitypharmacy.scot.nhs.uk/documents/nhs_boards/lothian/hep_c/Hepatitis_C_Service_Spec_2016-17_v1FINAL_pdf

29 Campbell Jl, Eyal N, Musiimenta A, Haberer JE. Ethical questions in medical electronic adherence monitoring. J Gen Intern Med 2016;31:338-42. doi: 10.1007/s11606-015-3502-4 pmid: 26358284

$30 \mathrm{Kim}$ J, Kassels AC, Costin NI, Schmidt H. Remote monitoring of medication adherence and patient and industry responsibilities in a learning health system. J Med Ethics 2020;46:386-91. doi: 10.1136/medethics-2019-105667 pmid: 32366704

31 Klugman CM, Dunn LB, Schwartz J, Cohen IG. The ethics of smart pills and self-acting devices: autonomy, truth-telling, and trust at the dawn of digital medicine. Am J Bioeth 2018;18:38-47. doi: 10.1080/15265161.2018.1498933 pmid: 30235091

32 Relton C, Strong M, Li J. The 'pounds for pounds' weight loss financial incentive scheme: an evaluation of a pilot in NHS Eastern and Coastal Kent. J Public Health (Oxf) 2011;33:536-42. do: 10.1093/pubmed/fdr030 pmid: 21447522

33 Radley A, Ballard P, Eadie D, MacAskill S, Donnelly L, Tappin D. Give it up for baby: outcomes and factors influencing uptake of a pilot smoking cessation incentive scheme for pregnant women. BMC Public Health 2013;13:343. doi: 10.1186/1471-2458-13-343 pmid: 23587161

34 Dinh CT, Bartholomew T, Schmidt H. Is it ethical to incentivize mammography screening in medicaid populations?-A policy review and conceptual analysis. Prev Med 2021;148:106534. doi: 10.1016/j.ypmed.2021.106534 pmid: 33771562

35 Bachman Desilva M, Gifford AL, Keyi X, etal. Feasibility and acceptability of a real-time adherence device among HIV-positive IDU patients in China. Aids Res Treat 2013;2013:957862. doi: 10.1155/2013/957862 pmid: 23956851

36 Thomas BE, Kumar JV, Onongaya C, etal. Explaining differences in the acceptability of 99DOTS, a cell phone-based strategy for monitoring adherence to tuberculosis medications: qualitative study of patients and health care providers. MIR Mhealth Uhealth 2020;8:e16634. doi: 10.2196/16634 pmid: 32735220

37 UK Government. Public Health (Control of Disease) Act. 1984. Sections 35, 37 and 38. 
38 Sekalala S, Forman L, Habibi R, Meier BM. Health and human rights are inextricably linked in the COVID-19 response. BMJ Glob Health 2020;5:e003359.

doi: 10.1136/bmigh-2020-003359 pmid: 32938607

39 Department of Health and Social Care. The NHS Constitution for England. 2015.

https://www.gov.uk/government/publications/the-nhs-constitution-for-england/the-nhs-constitution-for-england

40 Burkitt R, Duxbury K, Evans H, et al. The public and the NHS: what's the deal? 2018.

https://www.kingsfund.org.uk/sites/default/files/2018-06/The_public_and_the_NHS_report_0.pdf

41 Trueman P, Lowson K, Blighe A, et al. Evaluation of the scale, causes and costs of waste medicines. 2010. https://discovery.ucl.ac.uk/id/eprint/1350234/1/Evalua-

tion_of_NHS_Medicines_Waste_web_publication_version.pdf

42 Haskell H. Cumberlege review exposes stubborn and dangerous flaws in healthcare. BMJ 2020;370:m3099. doi: 10.1136/bmi.m3099 pmid: 32763955

43 Association of the British Pharmaceutical Industry (ABPI), National Institute for Health and Clinical Excellence (NICE). Agreement between the ABPI and NICE on guidelines for the release of company data into the public domain during a health technology appraisal. 2011.

https://www.nice.org.uk/Media/Default/About/what-we-do/NICE-guidance/NICE-technology-appraisals/Guidelines-for-the-release-of-company-data-into-the\%20public-domain-during-a-healthtechnology-appraisal.pdf

44 Osipenko L. Audit of data redaction practices in NICE technology appraisals from 1999 to 2019 BMJ Open 2021;11:e051812. pmid: 34615680 